\title{
Functionally gradient isotropic cylindrical shell locally heated by heat sources
}

\author{
Musii R. S. ${ }^{1}$, Zhydyk U. V. ${ }^{1}$, Mokryk O. Ya. ${ }^{2}$, Melnyk N. B. ${ }^{1}$ \\ ${ }^{1}$ Lviv Polytechnic National University, \\ 12 S. Bandera Str., 79013, Lviv, Ukraine \\ ${ }^{2}$ Danylo Halytsky Lviv National Medical University, \\ 69 Pekarska Str., 79010, Lviv, Ukraine
}

(Received 26 September 2019; Revised 20 July 2019; Accepted 23 July 2019)

\begin{abstract}
The stress-strain state of a functionally gradient isotropic thin circular cylindrical shell under local heating by a flat heat source has been investigated. For this purpose, a mathematical model of the classical theory of inhomogeneous shells has been used. A two-dimensional heat equation is derived under the condition of a linear dependence of the temperature on the transverse coordinate. The solutions of the non-stationary heat conduction problem and the quasi-static thermoelasticity problem for a finite closed cylindrical pivotally supported shell have been obtained by means of methods of Fourier and Laplace integral transforms. Numerical results are presented for the metal-ceramic composite used to restore the integrity of human tooth crowns.
\end{abstract}

Keywords: thermoelasticity, functionally gradient materials, temperature load, cylindrical shell.

2000 MSC: $74 \mathrm{~K} 25$

UDC: 539.3

DOI: $10.23939 / \mathrm{mmc} 2019.02 .367$

\section{Introduction}

Composite cylindrical shells, as important elements of many modern constructions, are often subjected to rapid-action temperature fields that can cause significant stresses and deformations. Therefore, the calculation of temperature stresses in such structures is an important scientific task that is still of interest of engineers. Especially in recent decades, the attention has been paid to the shell of an inhomogeneous structure [1-3] (laminated and functionally gradient (FG)), which, due to good thermal-resistant and rigid properties, became irreplaceable in modern technologies.

The temperature stresses in the elements of structures of FG materials were studied on the basis of both three-dimensional equations of thermoelasticity $[4,5]$ and two-dimensional ones [6-8]. The equations of interrelated thermoelasticity [6] and numerical methods of calculation [6,9] were also used. The more detailed overview of the various models is given in the papers $[10,11]$.

The purpose of this paper is to investigate the influence of parameters of heterogeneity on the stressstrain state of an isotropic circular cylindrical shell under its local heating by heat sources distributed along the guiding arc using the equations of thermal elasticity and conductivity of the classical shell theory.

\section{The problem formulation and the basic equations}

Let us consider an inhomogeneous isotropic circular cylindrical shell with the length $l$ and the constant thickness $2 h$. The points of the shell belong to a cylindrical coordinate system $x, \theta, z$, where $x$ is the axial coordinate, $\theta$ is the circle coordinate, $z$ is the radial coordinate. The origin of the coordinates is located on the middle surface with the radius $R$.

Let the shell be heated by sources of heat, which are the arbitrary functions of spatial coordinates and the time. The force load is absent. We investigate the thermoelastic state of the shell on the basis 
of the equations of the classical Kirchhoff-Love theory [12], which for a nonuniform material, we write in terms of displacements $u, v, w$

$$
L_{i 1} u+L_{i 2} v+L_{i 3} w=b_{i}, \quad i=1,2,3 .
$$

Here, the differential operators $L_{i j}\left(L_{i j}=L_{j i}\right)$ and the absolute terms $b_{i}$ have the form

$$
\begin{aligned}
L_{11} & =A\left(\partial_{11}^{2}+(1-\nu) /\left(2 R^{2}\right) \partial_{22}^{2}\right), \quad L_{12}=(A(1+\nu) / 2+B / R) / R \partial_{12}^{2}, \\
L_{13} & =\nu A / R \partial_{1}-B \partial_{1}\left(\partial_{11}^{2}+1 / R^{2} \partial_{22}^{2}\right), \\
L_{22} & =(1-\nu)\left(A+4 B / R+4 D / R^{2}\right) / 2 \partial_{11}^{2}+\left(A+2 B / R+D / R^{2}\right) / R^{2} \partial_{22}^{2}, \\
L_{23} & =(A+B / R) / R^{2} \partial_{2}-(B+D / R) / R^{3} \partial_{222}^{3}-(B+(2-\nu) D / R) / R \partial_{112}^{3}, \\
L_{33} & =A / R^{2}-2 B\left(\nu \partial_{11}^{2}+1 / R^{2} \partial_{22}^{2}\right) / R+D\left(\partial_{1111}^{4}+2 / R^{2} \partial_{1122}^{4}+1 / R^{4} \partial_{2222}^{4}\right), \\
b_{1} & =A^{t} \partial_{1} T_{1}+B^{t} / h \partial_{1} T_{2}, \\
b_{2} & =\left(A^{t}+B^{t} / R\right) / R \partial_{2} T_{1}+\left(B^{t}+D^{t} / R\right) /(R h) \partial_{2} T_{2}, \\
b_{3} & =\left(A^{t} / R-B^{t}\left(\partial_{11}^{2}+1 / R^{2} \partial_{22}^{2}\right)\right) T_{1}+\left(B^{t} / R-D^{t}\left(\partial_{11}^{2}+1 / R^{2} \partial_{22}^{2}\right)\right) / h T_{2},
\end{aligned}
$$

where

$$
\begin{gathered}
\{A, B, D\}=\frac{1}{1-\nu^{2}} \int_{-h}^{h} E(z)\left\{1, z, z^{2}\right\} d z ;\left\{A^{t}, B^{t}, D^{t}\right\} \quad=\frac{1}{1-\nu} \int_{-h}^{h} E(z) \alpha^{t}(z)\left\{1, z, z^{2}\right\} d z \\
T_{i}=\frac{2 i-1}{2 h^{i}} \int_{-h}^{h} t z^{i-1} d z \quad(i=1,2) ; \quad t=T_{1}+\frac{z}{h} T_{2} ; \quad \partial_{1}=\frac{\partial}{\partial x} ; \quad \partial_{2}=\frac{\partial}{\partial \theta}
\end{gathered}
$$

$E(z)$ is a modulus of elasticity; $\alpha^{t}(z)$ is the coefficient of thermal linear expansion; $\nu$ is the Poisson's coefficient; $t$ is the increase in temperature.

The system of equations (1) with the boundary conditions [12] forms the boundary value problem of temperature stresses for isotropic inhomogeneous cylindrical shells in terms of displacements.

The integral temperature characteristics $T_{1}, T_{2}$ of the absolute terms of the system (1) we determine from the corresponding equations of heat conduction under the boundary conditions imposed on the surfaces and on the edges of the shell. Under the equal conditions of heat exchange on the surfaces $z= \pm h$ of the shell, the equations of heat conduction have the following form

$$
\begin{gathered}
\Delta_{-(1)} T_{1}+\Delta_{-(2)} T_{2}+\frac{\Lambda_{(1)}}{R h} T_{2}-C_{(1)} \partial_{\tau} T_{1}-C_{(2)} \partial_{\tau} T_{2}-2 \alpha_{z}\left(T_{1}-t_{z}\right)=-W_{1}^{t}, \\
\Delta_{(2)} T_{1}+\Delta_{(3)} T_{2}-\frac{\Lambda_{(1)}}{h^{2}} T_{2}+\frac{\Lambda_{(2)}}{R h} T_{2}-C_{2} \partial_{\tau} T_{1}-C_{(3)} \partial_{\tau} T_{2}-2 \alpha_{z} T_{2}=-W_{2}^{t},
\end{gathered}
$$

where $\Delta_{(i)}=\Lambda_{(i)}\left(\partial_{11}^{2}+\partial_{22}^{2} / R^{2}\right) ;\left\{\Lambda_{(i)}, C_{(i)}, W_{i}^{t}\right\}=\int_{-h}^{h}\left\{\lambda(z), c_{\varepsilon}(z), w_{t}\right\}\left(\frac{z}{h}\right)^{i-1} d z,(i=1,2,3) ; \partial_{\tau}=$ $\frac{\partial}{\partial \tau} ; \lambda(z)$ coefficient of thermal conductivity; $c_{\varepsilon}(z)$ is the specific heat; $t_{z}$ is the ambient temperature on the surfaces $z= \pm h ; \alpha_{z}$ is the heat transfer coefficient; $w_{t}(x, \theta, z, \tau)$ is the density of heat sources; $\tau$ is a time variable.

\section{Method of solving}

For unambiguity of the solution of systems of equations of thermoelasticity (1) and of thermal conductivity (2), we impose the following boundary conditions on the edges $x=0$ and $x=l$ :

$$
\begin{gathered}
v=w=0, \quad \partial u / \partial x=\partial^{2} w / \partial x^{2}=0, \\
T_{1}=T_{2}=0
\end{gathered}
$$


as well as homogeneous initial conditions for temperature characteristics:

$$
\left\{T_{1}, T_{2}\right\}_{\tau=0}=0
$$

Let the shell is heated by the heat sources, whose functions we write in the following form

$$
W_{i}^{t}(x, \theta, \tau)=W_{i}^{z}(x, \theta) \cdot W_{i}^{\tau}(\tau) \quad(i=1,2) .
$$

Assume also that the ambient temperature on the surfaces is zero, and the specific heat of the shell material is constant. Then, applying to the system of equations (2) the Laplace integral transformation with respect to time and the double finite Fourier transform with respect to coordinates in accordance with conditions (4), (5), we obtain the expressions of the Fourier coefficients for the integral temperature characteristics

$$
\begin{aligned}
& T_{1 m n}=\frac{R^{2}}{2 h \lambda_{0}} \sum_{i \neq j=1}^{2} \frac{\left(p_{i}-g_{4}\right) Q_{1 m n} Z_{1 i}\left(\tau^{\prime}\right)+3 g_{2} Q_{2 m n} Z_{2 i}\left(\tau^{\prime}\right)}{p_{i}-p_{j}}, \\
& T_{2 m n}=\frac{R^{2}}{2 h \lambda_{0}} \sum_{i \neq j=1}^{2} \frac{3\left(p_{i}-g_{1}\right) Q_{2 m n} Z_{2 i}\left(\tau^{\prime}\right)+g_{3} Q_{1 m n} Z_{1 i}\left(\tau^{\prime}\right)}{p_{i}-p_{j}},
\end{aligned}
$$

where

$$
\begin{gathered}
p_{i}=\frac{g_{1}+g_{4}}{2}+(-1)^{i} \sqrt{\frac{\left(g_{1}-g_{4}\right)^{2}}{4}+g_{2} g_{3}} ; \quad g_{1}=\beta_{1}\left(\mu_{n}^{2}+m^{2}\right)+\mathrm{Bi} / \delta^{2} ; \\
g_{2}=\beta_{2}\left(\mu_{n}^{2}+m^{2}\right)-\beta_{1} / \delta ; \quad g_{3}=3 \beta_{2}\left(\mu_{n}^{2}+m^{2}\right) ; \\
g_{4}=3\left(\beta_{3}\left(\mu_{n}^{2}+m^{2}\right)+\left(\beta_{1}+\mathrm{Bi}\right) / \delta^{2}-\beta_{2} / \delta\right) ;
\end{gathered}
$$

$\mu_{n}=\frac{\pi n R}{l} ; \mathrm{Bi}=\frac{\alpha_{z} h}{\lambda_{0}} ; \tau^{\prime}=\frac{\lambda_{0} \tau}{c_{\varepsilon} R^{2}} ; \delta=\frac{h}{R} ; \beta_{i}=\frac{\Lambda_{(i)}}{2 h \lambda_{0}} ; \lambda_{0}$ is a characteristic coefficient of thermal conductivity;

$$
\begin{aligned}
Q_{j m n} & =\frac{k_{0}}{\pi l} \int_{0}^{l} \int_{-\pi}^{\pi} W_{j}^{z}(x, \theta) \sin \frac{\pi n}{l} x \cdot \cos m \theta d x d \theta, \quad k_{0}=\left\{\begin{array}{ll}
1, & m=0 \\
2, & m \neq 0
\end{array} ;\right. \\
Z_{j i}\left(\tau^{\prime}\right) & =\int_{0}^{\tau^{\prime}} W_{j}^{\tau}(v) e^{-p_{i}\left(\tau^{\prime}-v\right)} d v \quad(j, i=1,2) .
\end{aligned}
$$

The temperature characteristics in terms of the Fourier coefficients are expressed by formulas

$$
\left\{T_{1}, T_{2}\right\}=\sum_{n=1}^{\infty} \sum_{m=0}^{\infty}\left\{T_{1 m n}, T_{2 m n}\right\} \sin \frac{\pi n}{l} x \cdot \cos m \theta .
$$

The solution of the system of equations of equilibrium (1) which satisfies the boundary conditions (3), in the known temperature field (7) we determine also by means of the method of finite dual Fourier transformation with respect to the coordinates $x, \theta$. Then the components of the displacements $u, v, w$ in terms of the Fourier coefficients we obtain in the following form

$$
\begin{aligned}
u & =\sum_{n=0}^{\infty} \sum_{m=0}^{\infty} U_{m n} \cos \frac{\pi n}{l} x \cdot \cos m \theta \\
v & =\sum_{n=1}^{\infty} \sum_{m=1}^{\infty} V_{m n} \sin \frac{\pi n}{l} x \cdot \sin m \theta \\
w & =\sum_{n=1}^{\infty} \sum_{m=0}^{\infty} W_{m n} \sin \frac{\pi n}{l} x \cdot \cos m \theta
\end{aligned}
$$


By means of the known components of displacement (8) and the integral characteristics of the temperature field (7), we determine the internal efforts $N_{1}, N_{2}, S$, moments $M_{1}, M_{2}, H$ and stresses $\sigma_{i j}$ according to the formulas:

$$
\begin{gathered}
\left(\begin{array}{c}
N_{1} \\
N_{2} \\
M_{1} \\
M_{2}
\end{array}\right)=\left(\begin{array}{cccc}
A & A \nu & -B & B \nu \\
A \nu & A & -B \nu & B \\
B & B & -D & D \nu \\
B & B & -D \nu & D
\end{array}\right)\left(\begin{array}{c}
\partial_{1} u \\
\left(\partial_{2} v+w\right) / R \\
\partial_{11}^{2} w \\
\left(\partial_{2} v-\partial_{22}^{2} w\right) / R^{2}
\end{array}\right)-\left(\begin{array}{c}
A^{t} \\
A^{t} \\
B^{t} \\
B^{t}
\end{array}\right) T_{1}-\left(\begin{array}{c}
B^{t} \\
B^{t} \\
D^{t} \\
D^{t}
\end{array}\right) \frac{T_{2}}{h}, \\
\left(\begin{array}{c}
S \\
H
\end{array}\right)=\frac{1-\nu}{2}\left(\begin{array}{cc}
A & 2 B \\
B & 2 D
\end{array}\right)\left(\begin{array}{c}
\partial_{1} v+\partial_{2} u / R \\
\left(\partial_{1} v-\partial_{12}^{2} w\right) / R
\end{array}\right), \\
\left\{\begin{array}{l}
\sigma_{11} \\
\sigma_{22}
\end{array}\right\}=\frac{E(z)}{1-\nu^{2}}\left(\begin{array}{cc}
1 & \nu \\
\nu & 1
\end{array}\right)\left[\begin{array}{c}
\partial_{1} u_{1} \\
\left(\partial_{2} v+w\right) / R
\end{array}+z\left(\begin{array}{c}
-\partial_{11}^{2} w \\
\left(\partial_{2} v-\partial_{22}^{2} w\right) / R^{2}
\end{array}\right)\right]-\frac{E(z) \alpha^{t}(z)}{1-\nu} t, \\
\sigma_{12}=\frac{E(z)}{2(1+\nu)}\left[\partial_{1} v+\partial_{2} u / R+2 z\left(\partial_{1} v-\partial_{12}^{2} w\right) / R\right] .
\end{gathered}
$$

\section{Analysis of numerical results}

Numerical investigations is performed for a shell that is heated by heat sources constant in the thickness, which are distributed uniformly along the arc of the circle $|\theta| \leqslant \eta$ in the distance $x=x_{0}$. Then

$$
w_{t}(x, \theta, z, \tau)=w^{*} \delta\left(x-x_{0}\right)\left(S_{-}(\theta+\eta)-S_{+}(\theta-\eta)\right) S_{+}(\tau),
$$

where $w^{*}=$ const; $2 \eta$ is the central angle of the heating arc; $\delta(x)$ is the Dirac's function; $S_{ \pm}(x)$ are asymmetric unit functions.

The shell is made of functionally gradient composite of metal-ceramic, for which we assume that the Poisson's ratio and the specific heat are constant, and the modulus of elasticity $E(z)$, the coefficient of linear thermal expansion $\alpha^{t}(z)$, and the coefficient of thermal conductivity $\lambda(z)$ vary according to the power law depending on the coordinate $z[6]$ :

$$
\begin{gathered}
E(z)=E_{m}+\left(E_{c}-E_{m}\right)\left(\frac{z}{2 h}+\frac{1}{2}\right)^{k}, \quad \alpha^{t}(z)=\alpha_{m}^{t}+\left(\alpha_{c}^{t}-\alpha_{m}^{t}\right)\left(\frac{z}{2 h}+\frac{1}{2}\right)^{k}, \\
\lambda(z)=\lambda_{m}+\left(\lambda_{c}-\lambda_{m}\right)\left(\frac{z}{2 h}+\frac{1}{2}\right)^{k},
\end{gathered}
$$

where $k$ is the parameter of heterogeneity, which characterizes the change of the properties in the thickness of the shell; $c$ and $m$ are indices that indicate the belonging of quantities to ceramics or metal.

Physical and mechanical properties of ceramics $\left(\mathrm{ZrO}_{2}\right)$ and of metal (Ti-6Al-4V) we take as follow [6]:

$$
\begin{array}{ll}
\text { metal: } & \nu=0.3 ; E_{m}=66.2 \mathrm{GPa} ; \alpha_{m}^{t}=10.3 \cdot 10^{-6}{ }^{\circ} C^{-1} ; \lambda_{m}=18.1 \mathrm{~W} /\left(\mathrm{m} \cdot{ }^{\circ} C\right) ; \\
\text { ceramics: } & \nu=0.3 ; E_{c}=117 \mathrm{GPa} ; \alpha_{c}^{t}=7.11 \cdot 10^{-6}{ }^{\circ} C^{-1} ; \lambda_{c}=2.036 \mathrm{~W} /\left(\mathrm{m} \cdot{ }^{\circ} C\right) .
\end{array}
$$

For other parameters, we put the following values: $h / R=0.05, l / R=3, \eta=\pi / 2, x_{0}=l / 2, t_{z}=0$, $\mathrm{Bi}=0.2$.

For these parameters, we have calculated the dimensionless temperature characteristics $T_{i}^{\prime}=\frac{\lambda_{m} T_{i}}{h^{2} w^{*}}$, deflections $w^{\prime}=\frac{\lambda_{m} w}{R h^{2} \alpha_{m}^{t} w^{*}}$, normal efforts $N_{i}^{\prime}=\frac{\lambda_{m} N_{i}}{E_{m} h^{3} \alpha_{m}^{t} w^{*}}$, bending moments $M_{i}^{\prime}=\frac{\lambda_{m} M_{i}}{E_{m} h^{4} \alpha_{m}^{t} w^{*}}$ and normal stresses $\sigma_{i}^{\prime}=\frac{\lambda_{m} \sigma_{i i}}{E_{m} h^{2} \alpha_{m}^{t} w^{*}}$ depending on the circular coordinates $\theta$ for $x=l / 2$ and such values of parameters of heterogeneity: $k=0 ; 2 ; 5$ and $k=\infty$. It is obvious that with the decrease of the parameter $k$, the proportion of ceramics in the direction of thickness increases and the shell becomes 
more rigid since the modulus of elasticity of ceramics is larger than that one of metal. With the increase of $k$, the proportion of metal increases. The zero value of the parameter $k$ corresponds to a homogeneous shell made of ceramics, and that which is infinitely great corresponds to a homogeneous shell made of metal.

The changes of the average temperature $T_{1}^{\prime}$ and radial deflection $w^{\prime}$ are illustrated in Fig. 1.
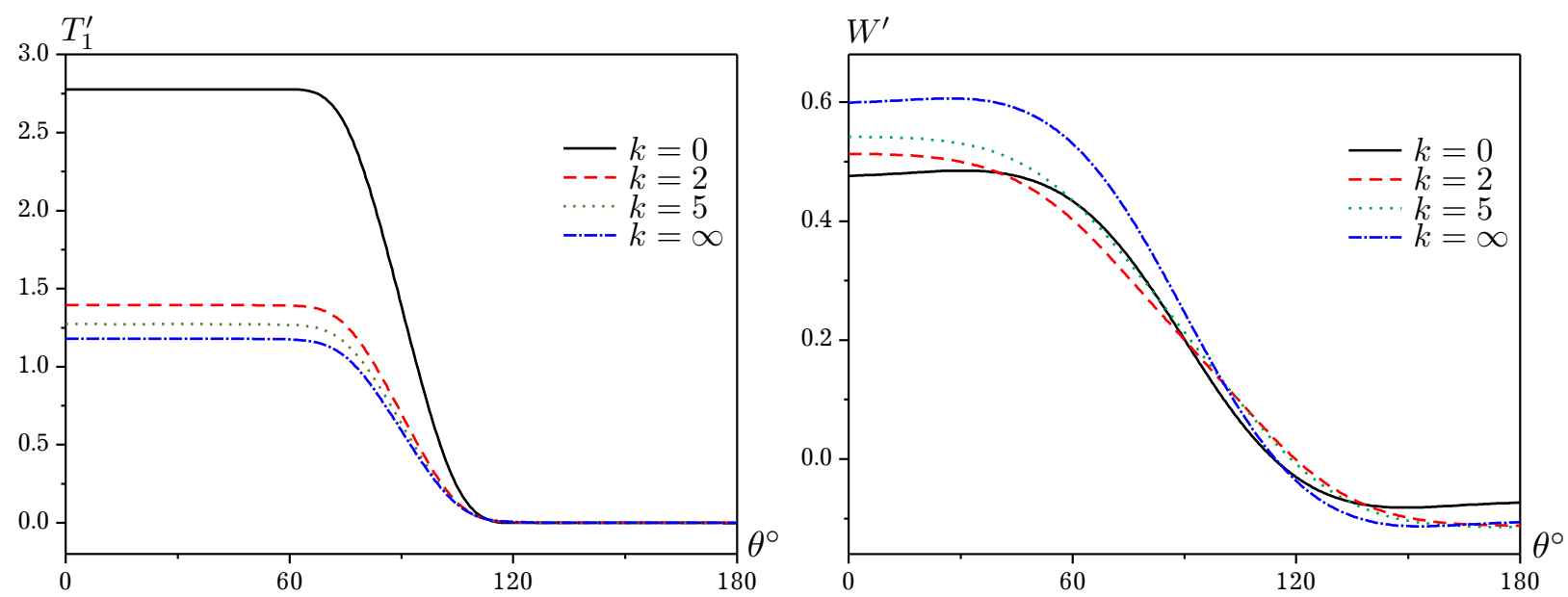

Fig. 1.

It can be seen from the figure that the average temperature for all materials is constant along the arc of the action of the sources, and the greatest value is achieved for ceramics. In transit to the unheated section, it drops sharply to the ambient temperature. The deflections gradually change from the greatest positive values in the heating area to the negative values in the unheated section. The maximal deflections reduce with an increase of the proportion of ceramics.
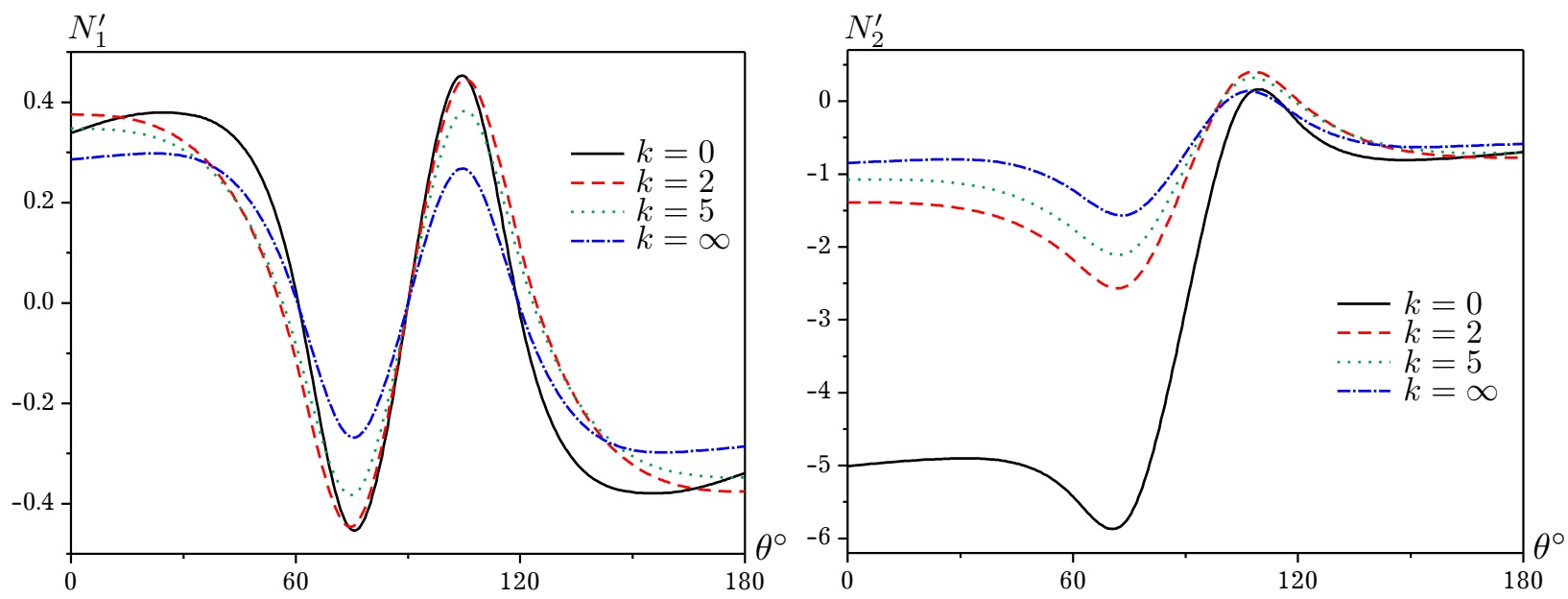

Fig. 2.

In Fig. 2, the changes of normal efforts $N_{1}^{\prime}$ and $N_{2}^{\prime}$ are shown. They are of oscillating nature. The effort $N_{1}^{\prime}$ in comparison with other parameters of stressed state has a feature that in the boundary zone between heated and unheated sections, they attain the same maximum compressive and tensile values. The maximal $N_{2}^{\prime}$ for all $k$ in the heating area is compressive, and for $k=0$ it is more than three times greater than for $k=\infty$.

Fig. 3 illustrates the monotonous nature of the change of bending moments $M_{1}^{\prime}$ and $M_{2}^{\prime}$ along the guide arc. The maximal positive values for ceramics are greatest and they decrease with the increase of the proportion of metal in the composite.

In Fig. 4, the dependence of normal stresses $\sigma_{1}^{\prime}$ and $\sigma_{2}^{\prime}$ on the circular coordinate on the surface of the shell $z=h$ is shown. It can be seen that the heterogeneity of the material can significantly change 

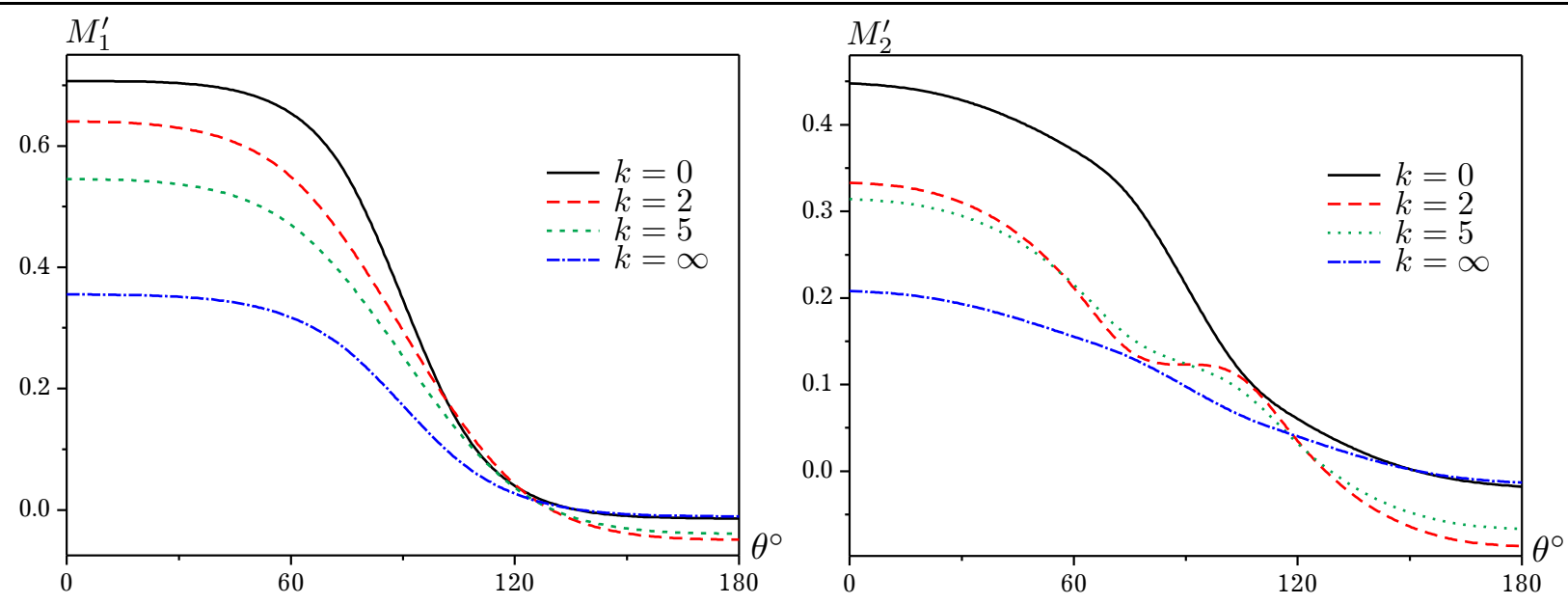

Fig. 3.
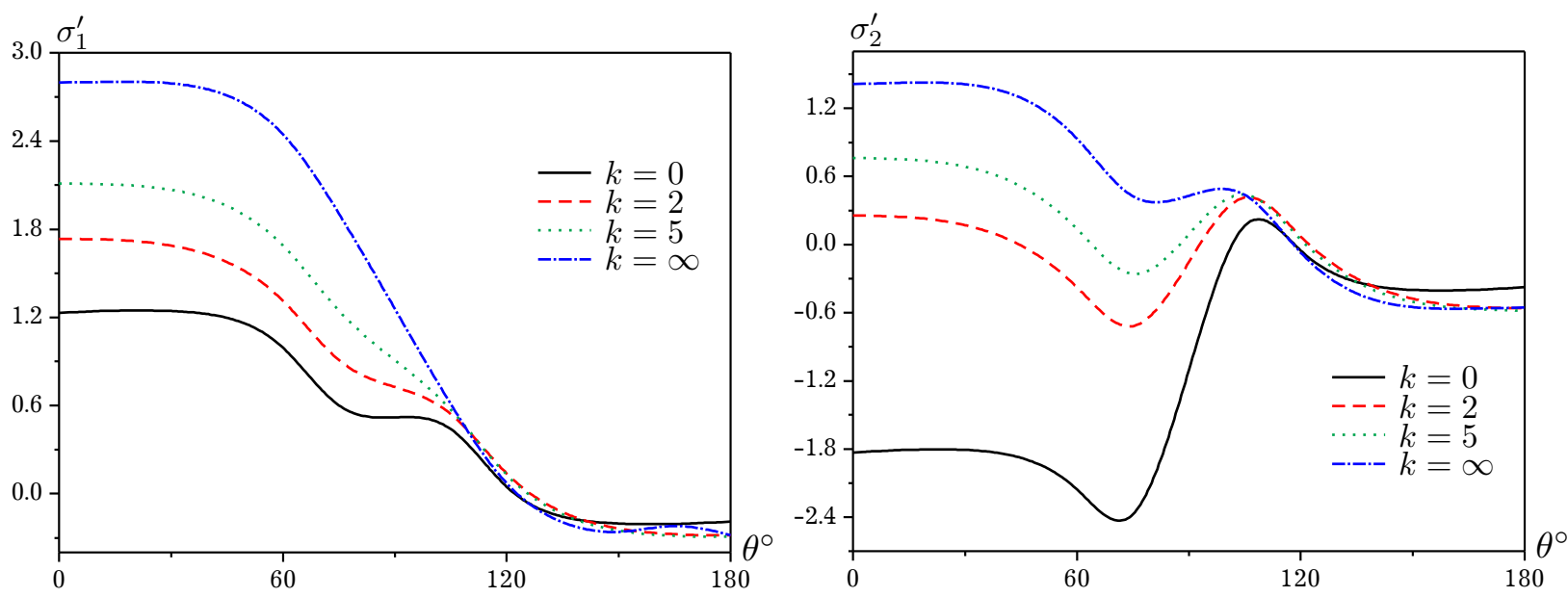

Fig. 4.

both the quantitative picture of the stress state and the qualitative one: the maximal $\sigma_{2}^{\prime}$ for $k=0$ is negative, and for $k=\infty$ it is positive.

\section{Conclusions}

Using the Kirchhoff-Love's linear theory of shells, we have investigated the stress-strain state of an isotropic functionally gradient closed circular cylindrical shell with the finite length, which is heated by a flat linear heat source acting along the guiding arc, whose edges are pivotally supported and of zero temperature. The physical and mechanical properties of the shell material are assumed to be arbitrary functions of the transverse coordinate. The quasistatic thermoelasticity problem has been solved by means of the finite double Fourier transform method with respect to the surface coordinates and by the Laplace integral transform with respect to time. Parameters of the stress-strain state have been calculated for a shell made of metal-ceramics composite, for which the modulus of elasticity, the coefficient of thermal linear expansion, and the coefficient of thermal conductivity vary in the thickness according to the power law. Numerical results describing the influence of the inhomogeneity parameter on the temperature field and on the stress-strain state of the shell are presented in the form of graphs.

[1] Zhydyk U. Mathematical modeling the thermomechanical behaviour of nonhomogeneous elastic anisotropic shells. Visnyk of the Lviv university. Ser. Mech-math. 57, 72-75 (2000), (in Ukrainian). 
[2] Zhydyk U., Nykolyshyn M., Flyachok V. Analysis of thermoelastic state of laminated anisotropic cylindrical shell under localized head sourced. Visnyk of the Lviv university. Ser. Mech-math. 73, 71-76 (2010), (in Ukrainian).

[3] Kushnir R. M., Nykolyshyn M. M., Zhydyk U.V., Flyachok V. M. Modeling of thermoelastic processes in heterogeneous anisotropic shells with initial deformations. J. Mathematical Sciences. 178 (5), 512-530 (2011).

[4] Ayoubi P., Alibeigloo A. Three-dimensional transient analysis of FGM cylindrical shell subjected to thermal and mechanical loading. J. Thermal Stresses. 40 (9), 1166-1183 (2017).

[5] Tokovyy Y. V., Chyzh A. I., Ma C. C. Thermal analysis of radially-inhomogeneous hollow cylinders vs cylindrical shells. Proceedings of the sixth ACMFMS. Taiwan. P. 216-219 (2018).

[6] Bahtui A., Eslami M. R. Coupled thermoelasticity of functionally graded cylindrical shells. Mechanics Research Communications. 34 (1), 1-18 (2007).

[7] Li D., Deng Z., Chen G., Ma T. Mechanical and thermal buckling of exponentially graded sandwich plates. J. Thermal Stresses. 41 (7), 883-902 (2018).

[8] Punera D., Kant T., Desai Y. M. Thermoelastic analysis of laminated and functionally graded sandwich cylindrical shells with two refined higher order models. J. Thermal Stresses. 41 (1), 54-79 (2018).

[9] PandeyS., PradyumnaS. Transient stress analysis of sandwich plate and shell panels with functionally graded material core under thermal shock. J. Thermal Stresses. 41 (5), 543-567 (2018).

[10] Birman V. L., Byrd W. Modeling and analysis of functionally graded materials and structures. Appl. Mech. Rev. 60, 195-216 (2007).

[11] Thai H. T., Kim S. E. A review of theories for the modeling and analysis of functionally graded plates and shells. Compos. Struct. 128, 70-86 (2015).

[12] Podstrigach Ya. S., Shvets R. N. Thermoelasticity of Thin Shells. Kyiv, Naukova Dumka (1978), (in Russian).

\title{
Функціонально-градієнтна ізотропна циліндрична оболонка за локального нагрівання джерелами тепла
}

\author{
Мусій Р. С. ${ }^{1}$, Жидик У. В. ${ }^{1}$, Мокрик О. Я. ${ }^{2}$, Мельник Н. Б. ${ }^{1}$ \\ ${ }^{1}$ Національний університет "Львівська політехніка", \\ вул. С. Бандери, 12, Львів, 79013, Украӥна \\ 2 Лъвівсъкий націоналъний медичний університет імені Данила Галицького, \\ вул. Пекарсъка, 69, Лъвів, 79010, Україна
}

\begin{abstract}
Досліджено напружено-деформований стан функціонально-градієнтної ізотропної кругової тонкої циліндричної оболонки за локального нагрівання плоским джерелом тепла. Для цього використано математичну модель класичної теорії неоднорідних оболонок. Двовимірне рівняння теплопровідності виведено за умови лінійної залежності температури від поперечної координати. Методами інтегральних перетворень Фур'є і Лапласа знайдено розв'язок нестаціонарної задачі теплопровідності та квазістатичної задачі термопружності для скінченної шарнірно опертої замкненої циліндричної оболонки. Числові результати наведено для композиту метал-кераміка, що використовується для відновлення цілісності коронок зубів людини.
\end{abstract}

Ключові слова: термопружність, функиіонально-градієнтні матеріали, температурне навантаження, ииліндрична оболонка.

2000 MSC: $74 \mathrm{~K} 25$

УдК: 539.3 